\title{
Epitheliocystis agents in sea bream Sparus aurata: morphological evidence for two distinct chlamydia-like developmental cycles
}

\author{
S. Crespo*, C. Zarza, F. Padrós, M. Marín de Mateo \\ Biologia Animal, Departament de Biologia Animal, Biologia Vegetal i d'Ecologia, Facultat de Veterinària, \\ Universitat Autònoma de Barcelona, E-08193 Bellaterra, Barcelona, Spain
}

\begin{abstract}
The morphology of membrane-bound intracellular inclusions, or 'cysts', of epitheliocystis from sea bream Sparus aurata is described. Inclusions under the light microscope appear either granular or amorphous. Granular inclusions do not elicit a proliferative host reaction and contain the 3 distinctive developmental stages of chlamydial organisms: the highly pleomorphic reproductive form or reticulate body, the condensing form or intermediate body and the infective non-dividing rather uniform elementary body. Amorphous inclusions may elicit a proliferative host reaction and contain prokaryotic organisms which differ morphologically from those reported within granular cysts. More or less elongated electron-lucent organisms divide by fission to give rise to electron-dense non-dividing small cells with a dense nucleoid. Vacuolated and non-vacuolated small cells are reported. The morphology and developmental cycle of sea bream epitheliocystis agents would support their chlamydial nature; however, the immunohistochemical study conducted on gill samples which carried both inclusions failed to demonstrate the expression of lipopolysaccharide (LPS) chlamydial antigen. The different stages of the 2 distinct developmental cycles described in the present study are compared with electron microscope observations of epitheliocystis organisms reported from different host species. The hypothesis that epitheliocystis infection in the sea bream might be caused by a unique highly pleomorphic chlamydia-like agent, the life history of which includes 2 entirely different developmental cycles, is discussed.
\end{abstract}

KEY WORDS: Gill pathology Sea bream - Epitheliocystis infection · Chlamydial organisms · Light and electron microscopy

\section{INTRODUCTION}

Epitheliocystis has been reported worldwide in numerous fish species from both fresh water and the marine environment, the gill being the most common, though not the sole, site of infection (see reviews by Turnbull 1993, Fryer \& Lannan 1994). The first description in sea bream Sparus aurata by Paperna (1977) reported the 'proliferative condition' of the disease in fish farms from Israel. Since then, epitheliocystis has been recorded in different sea bream culture facilities of the Mediterranean region (Paperna \& Baudin-Laurencin 1979, Paperna et al. 1981, Ceschia \& Makovec

·E-mail: ibiae@blues.uab.es
1995, Padrós \& Crespo 1995). Epitheliocystis in sea bream was first detected in Spain in 1990 (Crespo unpubl. data). Although, in this particular case, host reaction to epitheliocystis agents was 'benign' (i.e. non-proliferative), the infection was associated with trickling mortalities of $2 \mathrm{~g}$ fingerlings. Histopathological surveys carried out during a 6 yr period (1990 to 1995) in fish farms from the Catalan coast (northeast Spain) revealed the occurrence of chronic, non-pathogenic epitheliocystis infection in $80 \%$ of the sea bream samples examined (Padrós et al. 1995).

Acute proliferative epitheliocystis infections and mixed epitheliocystis-monogenean infections (ÁlvarezPellitero \& Crespo 1995, Padrós \& Crespo 1995) caused severe mortalities to sea bream from Spanish mariculture facilities in winter 1994. Epitheliocystis infection 
was also recorded in wild sea bream captured in 1994 from the Catalan coast (Padrós unpubl. data).

The nature of epitheliocystis causative agents in fish was speculative and its inclusion in the order of Chlamydiales was based solely on ultrastructural characteristics until the work by Groff et al. (1996), who demonstrated antigenic similarities between epitheliocystis organisms and chlamydiae in the white sturgeon Acipenser transmontanus. However, immunohistochemical studies have not been conclusive in other species (see review by Turnbull 1993), and Nylund et al. (1998) stated 'it is possible that the epitheliocystis agent described from different species represents at least two different agents - one rickettsial and the other chlamydial'. The morphological data available in the literature are numerous but fragmentary and therefore confusing. The aim of the present study was to compare histological and ultrastructural observations of epitheliocystis infected sea bream Sparus aurata to clarify the developmental cycle of the causative agents in this species. Immunohistochemical studies were carried out to elucidate the antigenic similarities, if any, of epitheliocystis organisms to the genus Chlamydia.

\section{MATERIAL AND METHODS}

Light microscope (LM) examination of H\&E stained gill sections of epitheliocystis infected sea bream Sparus aurata from fish farms located along the Spanish coast (149 positive samples; a total of 2157 fish examined; body weight 0.7 to $400 \mathrm{~g}$ ) revealed the existence of 2 morphologically different parasitic intracellular inclusions or cysts: (1) cysts with a granular basophilic content, which are referred to, in the present report, as 'granular cysts'; (2) cysts containing an amorphous homogenous basophilic material, which are termed 'amorphous cysts'.

Three different groups of epitheliocystis cases diagnosed at our laboratory were established with the criterion quoted above (i.e. granular-amorphous content of the cysts following LM examination): (1) infected fish which exhibited only the granular type inclusion; (2) samples with only amorphous cysts; and (3) samples which carried both kinds of cysts. Gill sections containing both inclusions were cut from paraffin blocks and stained with: Gram, periodic acid-Schiff, Macchiavello and Azan. Hyperinfected gill samples from each of the 3 groups were chosen for transmission electron microscopy (TEM). Paraffin blocks were deparaffinized in xylene overnight prior to rehydration through a graded ethanol series. Deparaffinized gill tissue was secondarily fixed in $4 \%$ glutaraldehyde buffered solution, post-fixed in $2 \%$ osmium tetroxide, serially dehydrated in graded ethanol, stained 'en bloc' with uranyl acetate and embedded in Epon or Spurr. Semithin and ultrathin sections were cut in a $\mathrm{LKB}$ Nova ultramicrotome and stained with toluidine blue and lead citrate, respectively. Ultrathin sections were examined on a Hitachi 7100 TEM. Formalin-fixed gill filaments from the same samples as those exhibiting only amorphous or only granular forms were chosen for scanning electron microscopy (SEM). Gill filaments were dehydrated through graded ethanol series, critical-point dried with liquid $\mathrm{CO}_{2}$, coated with gold, and viewed in a Hitachi S570 SEM. A standard peroxidaseantiperoxidase (PAP) immunohistochemical staining procedure was carried out on histological sections exhibiting the 2 types of inclusions. Details of the technique have already been described (Majó et al. 1995, Szeredi et al. 1996). Murine monoclonal antibodies directed against chlamydial genus-specific lipopolysaccharide (LPS) antigen, kindly provided by Dr J. Salinas (Departamento de Patología Animal, Universidad de Murcia, Spain), were used as primary antibody. Goat anti-mouse IgG-biotin (Dako, Denmark) and avidin-biotin peroxidase complex (Vector Lab., Burlingame, CA, USA) were utilized to visualize the reaction product. The antibodies were tested on each sample in various dilutions. Intestinal tissue from pigs infected by Chlamydia trachomatis, kindly provided by Dr F. Guscetti (Institute for Veterinary Pathology, Veterinary Medical Faculty, University of Zurich, Switzerland), were used as Chlamydia positive controls. Negative controls included use of phosphatebuffered saline instead of the primary antibody and gut tissues from non-infected pigs

\section{RESULTS}

\section{Light and scanning electron microscope observations}

LM studies revealed the heterogenicity of epitheliocystis granular inclusions (Fig. 1), granules being observed in H\&E stained sections (Fig. 1a) and on wet mounts (Fig. 1b). Amorphous cysts all exhibited the same appearance under the LM (Fig. 2a,b). Apart from the nature and heterogenicity of their contents the 2 types of inclusions differed in their staining affinities, morphology of their 'capsule', location in fish tissues, reaction they elicited in the host, and appearance in relation to the age of fish:

(1) Staining affinities. The stains revealed both inclusions as Gram and PAS negative. Granular cysts stained pale yellow or greyish with Azan (Fig. 1d,e) and were Macchiavello negative (Fig. 2c) whereas amorphous cysts stained deep orange with Azan (Fig. 2f) and positively with Macchiavello (Fig. 2c). 


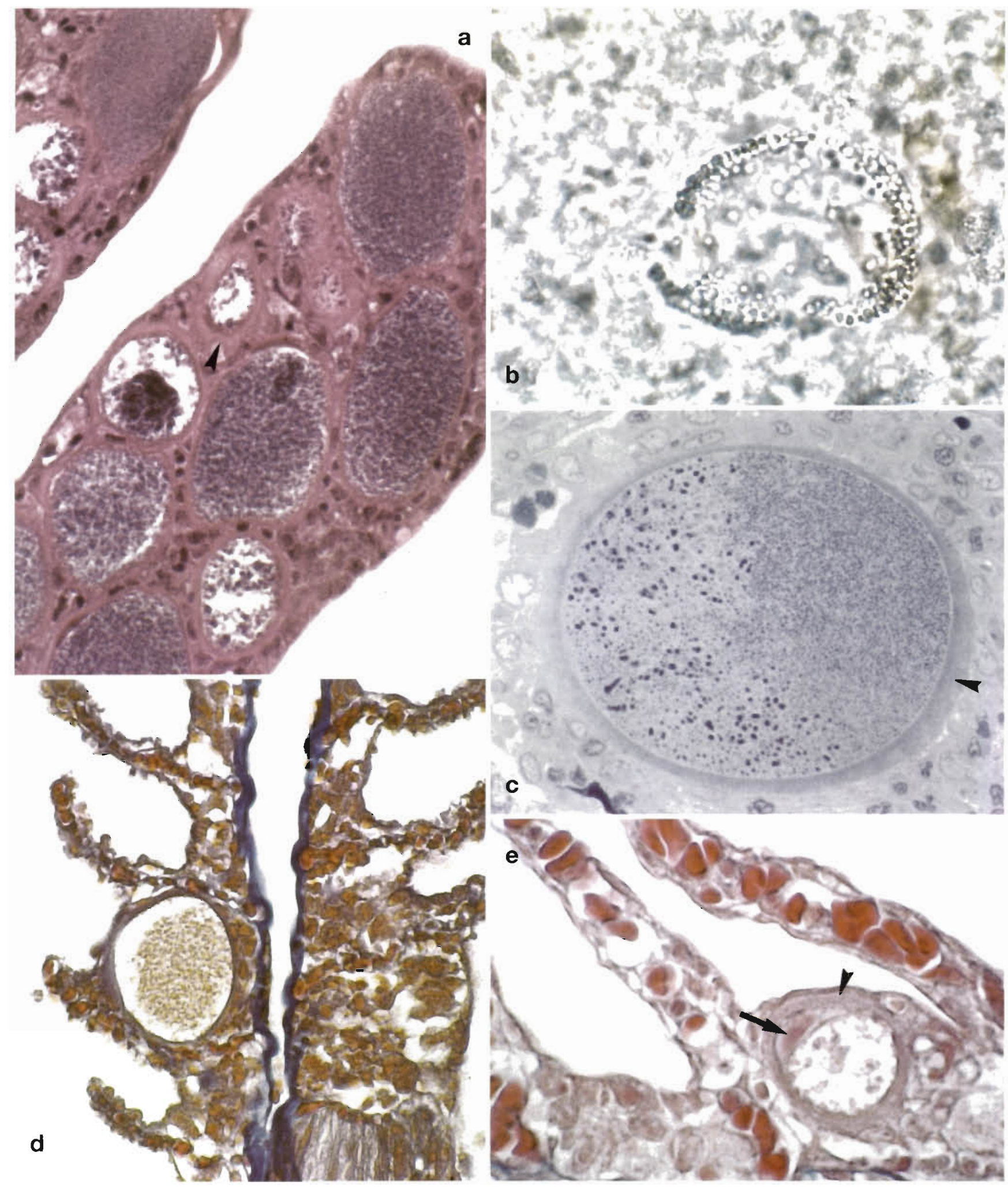

Fig. 1. Granular intracellular inclusions or cysts in the gills of epitheliocystis infected sea bream Sparus aurata. Note heterogenicity of granular cyst population in H\&E-stained sections $(a, \times 400)$ and presence of granules within cysts on wet mounts $(b, \times 1000)$. Different stages of development of epitheliocystis organisms are observed in toluidine blue-stained semithin sections (c, $\times 1000$ ) Prokaryotic organisms stain pale yellow or grey with Azan $\left(d_{1} \times 400 ; e_{,} \times 400\right)$. Arrowheads $(\mathrm{a}, \mathrm{c}$, and e) point to the cyst capsule and arrow (e) points to the nucleus of the host cell pushed to the periphery as parasitic inclusion enlarges 

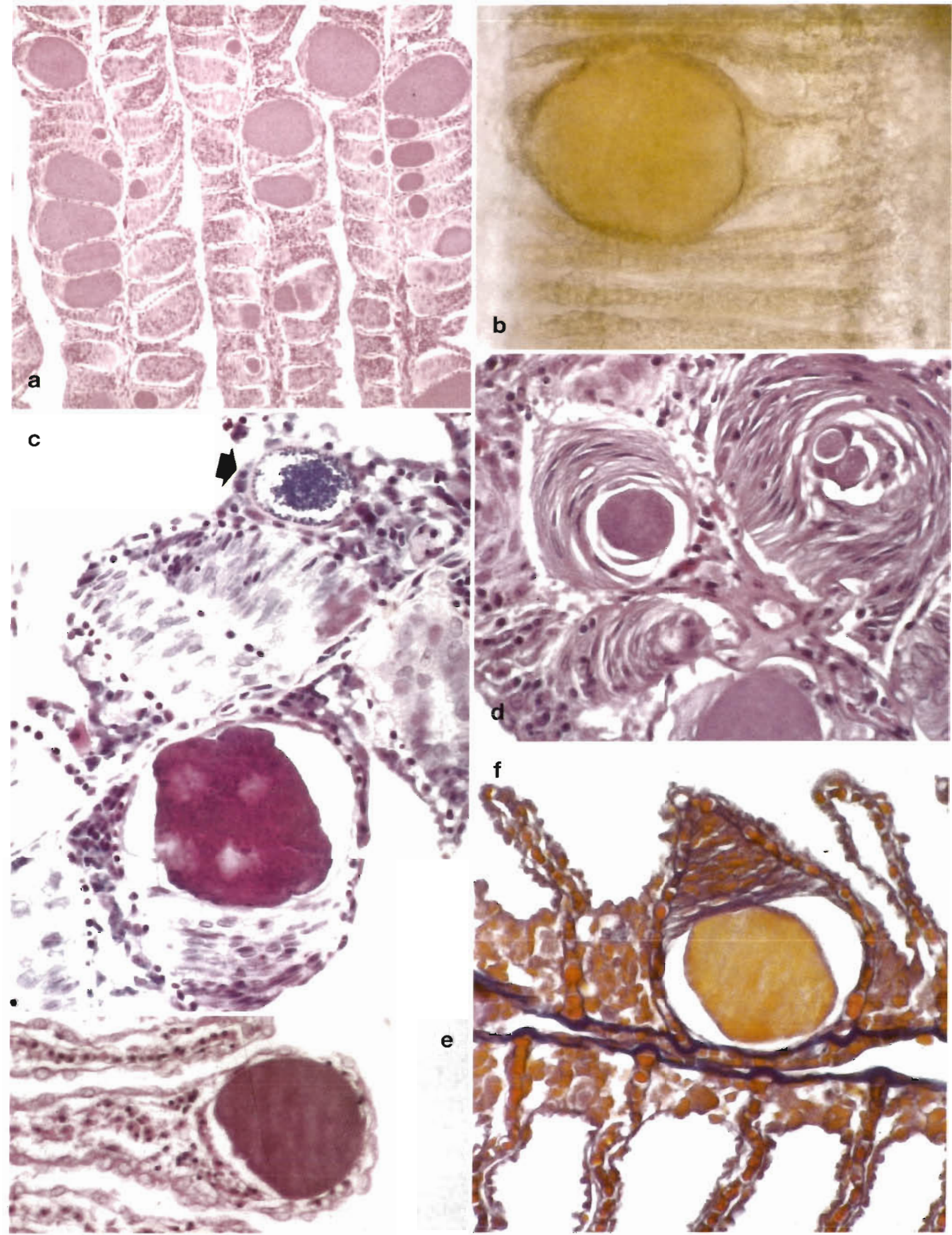

e
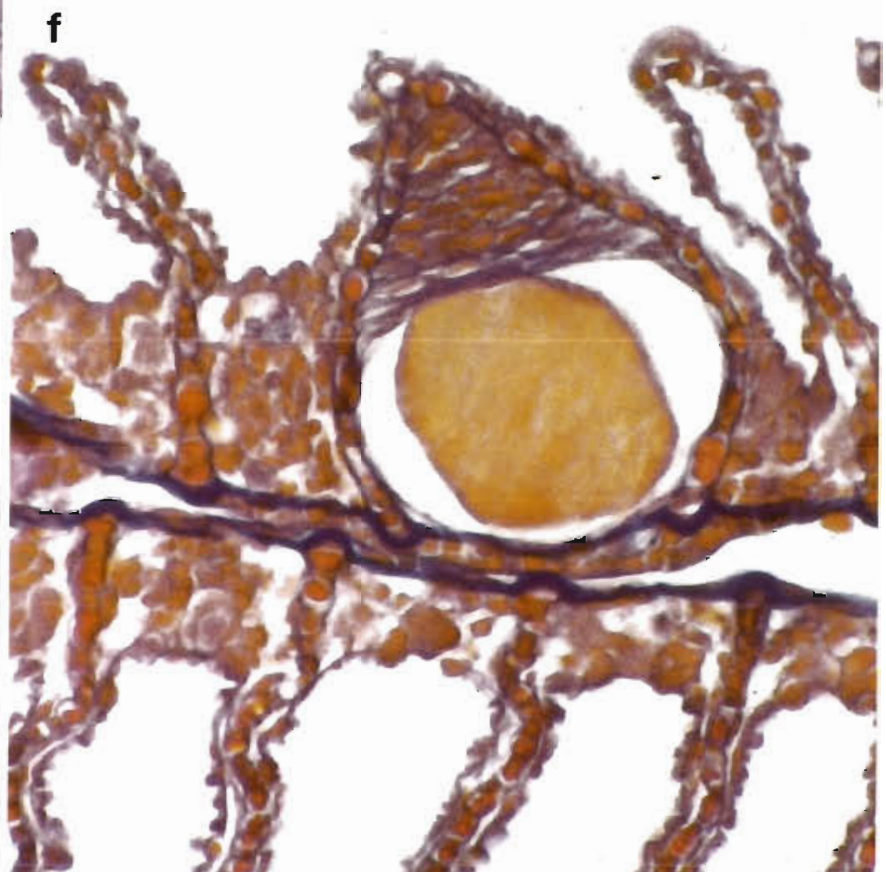
Fig. 2. Amorphous intracellular inclusions or cysts in the gills of epitheliocystis infected sea bream Sparus aurata. Note homogenicity in cyst content on H\&E-stained sections $(a, \times 100)$ and wet mounts $(b, \times 1000)$. Amorphous cysts stain positively with Macchiavello whereas granular cysts (arrow) are Macchiavello negative $(c, \times 400)$. In severely infected fish, amorphous cysts appear surrounded by a pseudocapsule of several concentric layers of epithelial tissue $(d, \times 400)$ whereas in mildly infected fish (e, $\times 400)$ epitheliocystis agents may not elicit a host reaction. Amorphous cysts stain deep orange with Azan (f, $\times 400$ )

(2) Morphology of the 'capsule'. As epitheliocystis inclusions enlarged within the infected cell, the nucleus was pushed to one side and increased in size (Fig. 1e). Infected cells with granular cysts seemed to be limited by a hyaline eosinophilic capsule which might correspond to the host cell cytoplasm undergoing degeneration (Fig. 1a,c,e). These capsules (Fig. 1a), appeared thicker around those granular cysts which exhibited a more heterogenous content (presumably initial-or immature-cysts). The thin capsule of the cysts containing a mass of uniformly sized densely packed particles (presumably mature cysts) corresponded to the infected cell cytoplasm compressed by an enlarging inclusion. On the contrary, amorphous cysts did not appear to be limited by any capsules (Fig. 2).

(3) Location. Under the LM, granular cysts were mainly found in the interlamellar spaces of the gill filament, at the base of the lamellae, where chloride cells are mainly located (Fig. 1d,e). SEM studies revealed that they could also be found in either the leading
(Fig. 3a) or trailing (Fig. 3b) edge of the gill filament. Occasionally, they were also encountered in the pseudobranch, the epithelial lining of the orobranchial cavity and nostrils, the epidermis of the skin, and the mucosa of the oesophagus. Amorphous cysts were also found in the interlamellar spaces (Fig. 2a) and, less frequently, along the leading and trailing edge of the gill filament. Occasionally, they were encountered in the pseudobranch and in the epithelial lining of the gill rakers. They were not found in either the skin or the digestive tract mucosa of any of the infected fish.

(4) Host reaction. Granular cysts were never shown to trigger any severe proliferative cell responses around them (Figs. $1 \& 2 \mathrm{c}$ ), host reaction being limited to a mild epithelial hyperplasia of the gill tissue. Amorphous cysts, particularly in hyperinfected fish, elicited proliferative cell responses around them, resulting in their embedding in a pseudocapsule of several concentric layers of epithelial tissue (Fig. 2d), and leading to lamellar fusion (Fig. 2a). In mildly infected fish, how-
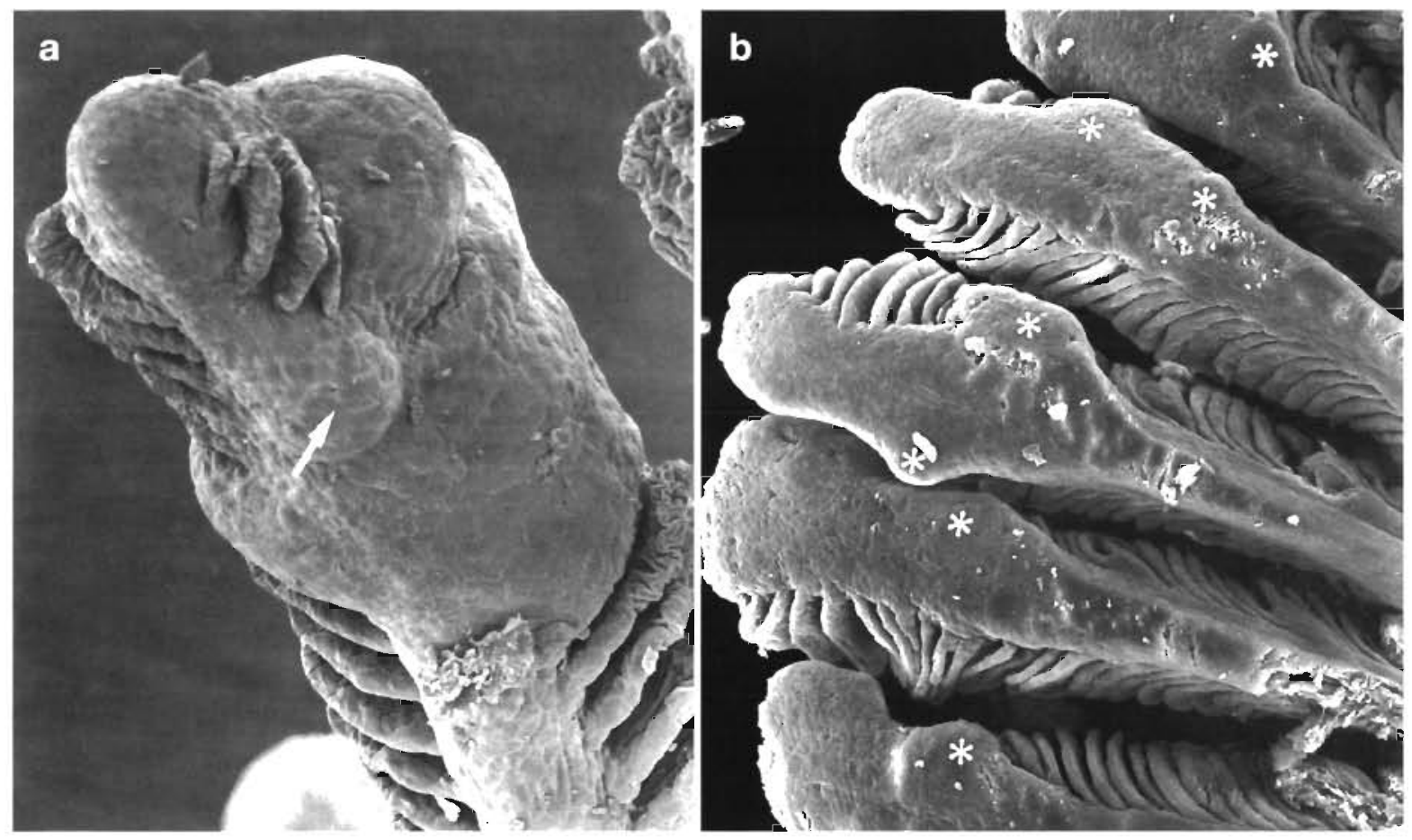

Fig. 3. Granular cysts in the gill filaments of epitheliocystis infected sea bream Sparus aurata. Note in (a) that cysts are mainly located in the interlamellar spaces, although they can also be found (arrow) along the leading edge of the gill filament $(\times 280)$ Cysts $(*)$ can also be encountered along the trailing edge of gill filaments $(b, \times 120)$ 


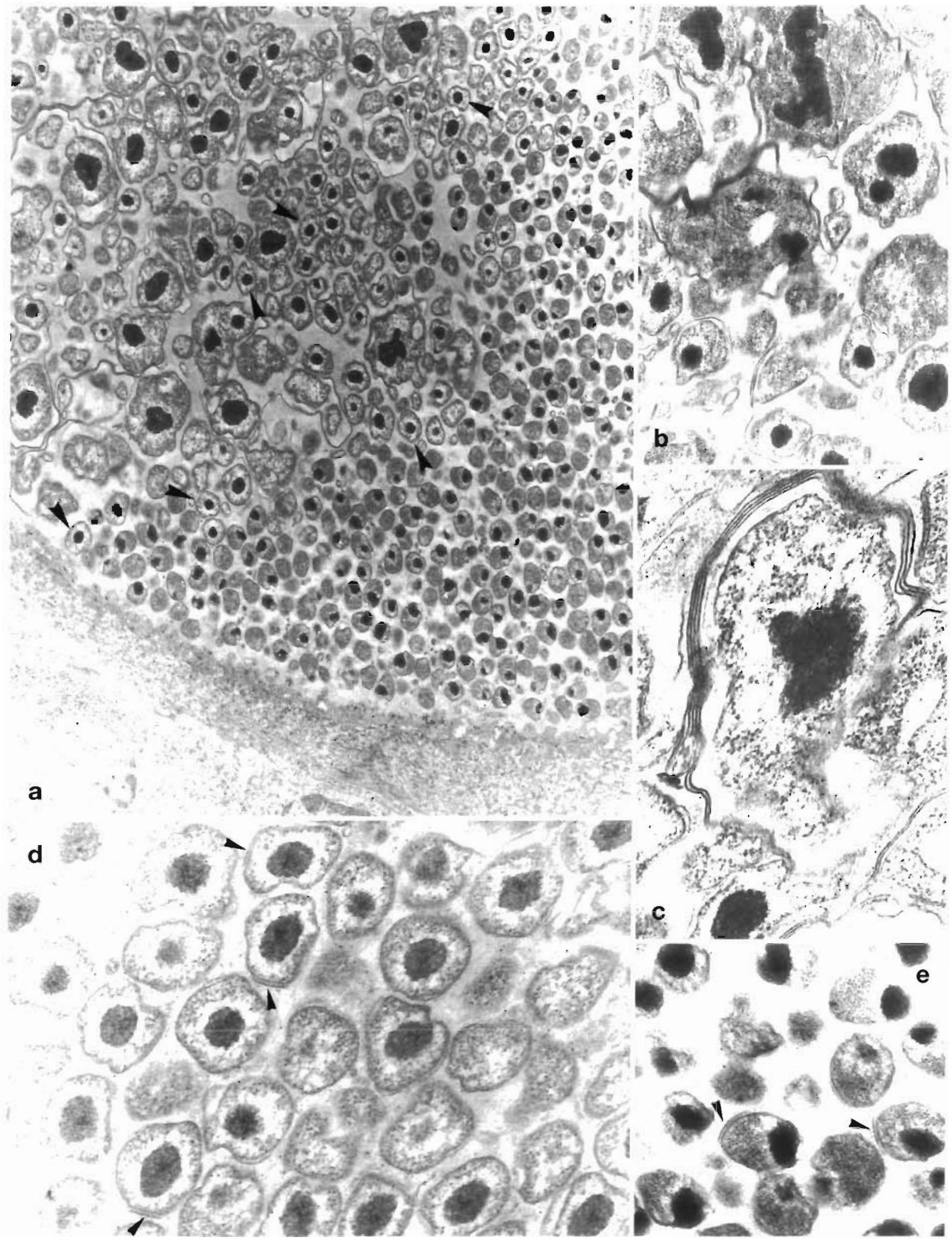

Fig 4. Chlamydia-like developmental cycle of sea bream Sparus aurata epıthelocystis agents within granular cysts (Cycle I) (a) Retıculate bodies (upper left part of the micrograph) give nse to intermediate bodies (arrowheads), and then elementary bodies (bottom nght) $\times 8000$. Reticulate bodies are highly pleomorphic, with 1 or more compact nucleolds $(b, \times 15600)$ and appear surrounded by several layers of cell membranes $\left(c_{1} \times 39000\right)$ Intermediate bodies exhibit a centrally located nucleold, ribosomes being concentrated at the perphery $(d, \times 32000)$. Elementary bodies are oval or bullet-shaped organisms with a dense eccentrically located nucleold $(e, \times 26000)$. Note in (d) and (e) that intermediate and elementary bodies are covered by electron-dense 
ever, they might (Fig. 2f) or might not (Fig. 2e) trigger a proliferative cell response around them.

(5) Appearance of the cysts in relation to the age of fish. Either mildly or hyperinfected, 0.7 to $2 \mathrm{~g}$ fingerlings were found to exhibit only the granular type of cyst. Epitheliocystis-infected juvenile sea bream carried both kinds of inclusions $(80 \%$ of the cases diagnosed). The oldest sea bream (1 case; $\mathrm{n}=15 ; 400 \mathrm{~g}$ weight) only exhibited amorphous cysts.

\section{Correlation between TEM and LM}

The LM study of semithin sections from samples which had been previously seen to carry only the granular type of cysts revealed the existence of morphologically different prokaryotic organisms (Fig. 1c). The TEM study of these cysts (Fig. 4) showed 3 distinct stages of intracellular development, similar to that of chlamydiales, and described as reticulate bodies ( $R B$; Fig, $4 b, c)$, intermediate bodies (IB; Fig. $4 \mathrm{~d}$ ) and elementary bodies (EB; Fig. 4e). Cysts which, under the LM, showed a uniform granular content (Fig. 1a) corresponded to inclusions which were regularly packed with EB. Cysts which showed less densely packed granules contained IB. Cysts with highly heterogenous irregularly distributed material contained RB and IB or the 3 developmental stages (Fig. 4a). Prokaryotic organisms all throughout their life cycle (Figs. 4 \& 5) exhibited a granular cytoplasm, with 1 or more cytoplasmic condensations and were limited by an outer cell wall and a cytoplasmic membrane. RB were highly pleomorphic and variable in size, with 1 or more compact nucleoids, also highly variable in size, and a reticulo-granular matrix of low to moderate density suggestive of ribosomes (Figs. 4b,c \& 5b). Some RB appeared surrounded by several layers of cell membranes (Fig. 4c) and divided by uneven fission or budding (Fig. 5a,b), creating smaller, more or less uniform spherical organisms (IB). IB exhibited a single centrally located compact nucleoid, ribosomes being concentrated in the peripheral region (Fig. 4d). Immature IB were observed in the process of division (Fig. 5c). Dividing IB could form single or branching chains of variable length. The membrane of the intracellular inclusion immediately adjacent to developing IB was infolded and dense (Fig. 5a). EB were observed as uniform oval or bullet-shaped organisms (Fig, $4 \mathrm{a}, \mathrm{e}$ ). These appeared closely spaced and regularly distributed within the inclusion and contained a more electrondense cytoplasm than IB, with a single very dense eccentrically located nucleoid surrounded by a translucent halo. Opposite to the nucleoid, a structure composed of arrayed fine fibrilar surface projections could be observed covering EB like a 'cap' (Fig. 4e). 'Caps' could be initially seen, although less apparent, in some mature IB (Fig. 4d), but were not observed in dividing IB (Fig. 5c).

The TEM study of amorphous inclusions revealed that they contained morphologically different pro-

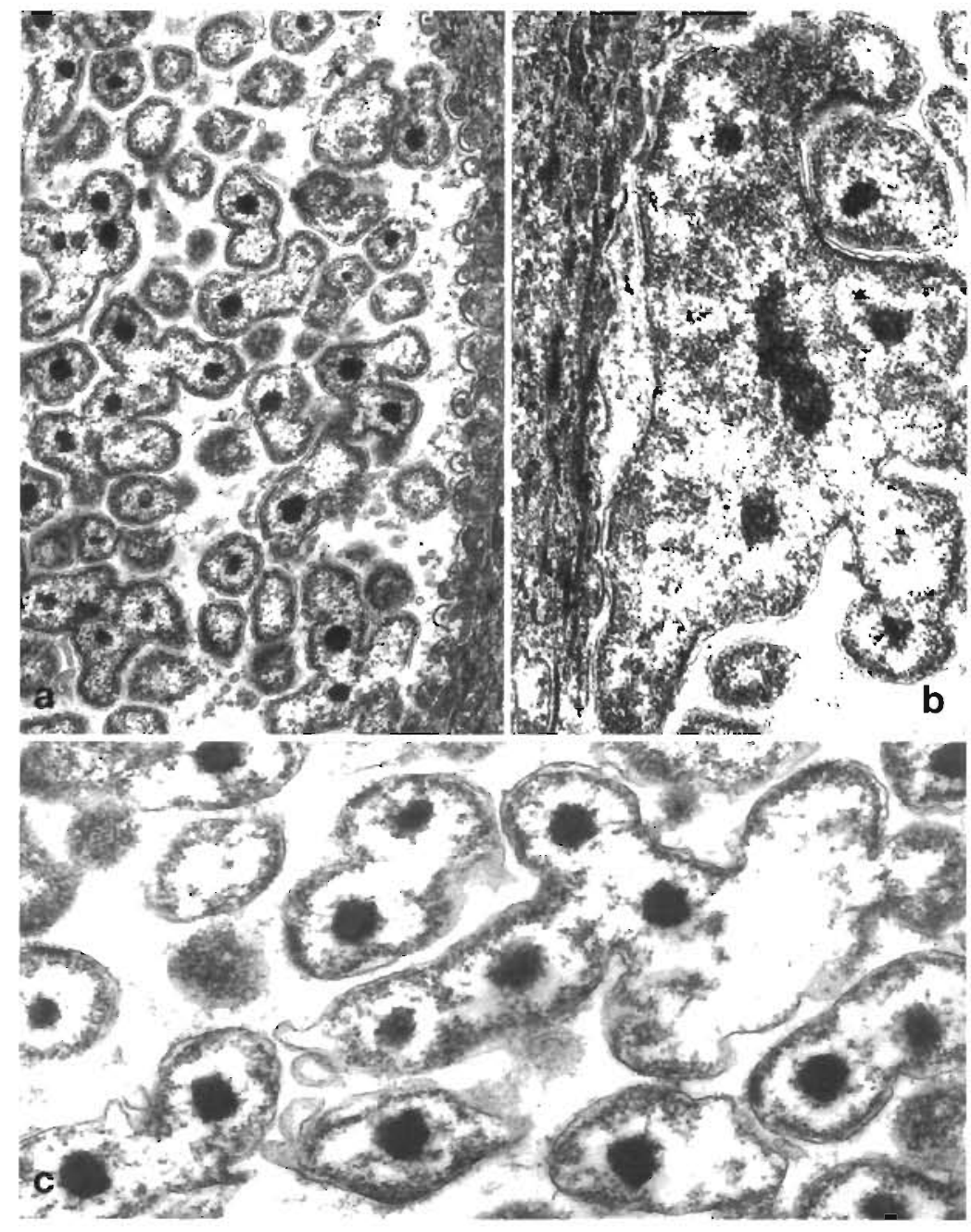

Fig. 5. Epitheliocystic agents in sea bream. Reproductive stages of Cycle I: reticulate and intermediate bodies. Note the membrane of the intracellular inclusion adjacent to dividing prokaryotes appears infolded $(a, \times 13000)$. Reticulate bodies divided by uneven fission or budding, producing intermediate bodies (b, $\times 22100$ ). Dividing intermediate bodies are able to form single or branching chains $(c, \times 27200)$ 


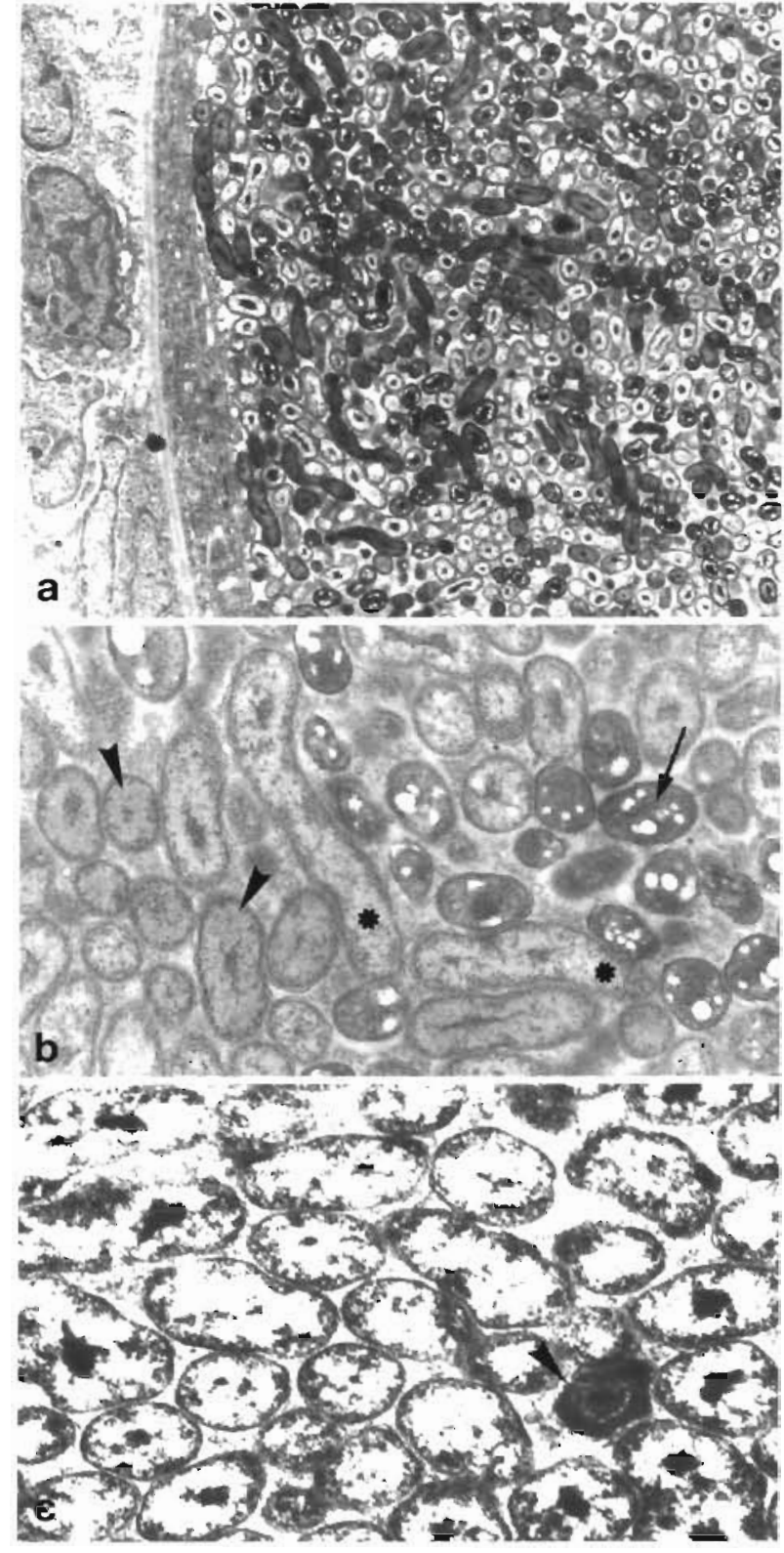

Fig. 6 Chlamydia-like developmental cycle of sea bream Sparus aurata epitheliocystis agents within amorphous cysts (Cycle II) Note pleomorphic organisms within cysts $(a, \times 3500)$ Three difterent developmental stages are distinguished in (b) primary long cells ( ), intermediate long cells (arrowheads) and vacuolated small cells (arrow) $(\times 11700)$ An electrondense non-vacuolated small cell (arrowhead) can be observed In $(c)(\times 19500)$

karyotıc organisms (Fig 6a) which differed from those described withın granular cysts. Their description (Fig. 6b) corresponded to that previously reported by Paperna et al (1981) in sea bream Sparus aurata the nckettsia-like elongated cells and the coccold small cells (SC). Elongated cells exhibited electron-lucent cytoplasm, nbosomes being mainly confined to the periphery of the cell, and were limited by a cell wall and a cytoplasmic membrane. Their nucleoid was a more or less loose fibrilar aggregate which became denser as the cells matured (i.e. as primary long cells [PLC] gave rise by fission to intermediate long cells [ILC]). Following division, all cells separated into individual units, neither branching structures, nor chains of connected organisms being observed. The SC, oval in shape, exhibited an electron-denser cytoplasm and a more compact, centrally located, round nucleoid. Vacvolated SC (Fig 6b) and non-vacuolated SC (Fig. 6c), smaller and electron-denser than the former, were observed. Inclusions containing PLC and ILC alone, and PLC, ILC and SC were found, but not SC alone. Nonvacuolated and vacuolated SC were not observed in the same inclusions. Non-vacuolated SC were only found within inclusions from hyperinfected fish which carried exclusively amorphous cysts ( 1 case $n=15$ ).

PLC, ILC and SC were seen randomly distributed within inclusions (Fig. 6a), suggesting asynchronic division of prokaryotic organisms. On the contrary, within some granular cysts (Figs. 1c \& 4a), the different organısms were stratified with $\mathrm{RB}$ and dividing $\mathrm{IB}$ at one side of the inclusion, while the opposite side consisted almost entirely of EB, suggesting a certain synchronicity of the division process. The size of the different stages of sea bream epitheliocystis agents is given in Table 1 . The forms of epitheliocystis reported in the literature from different species of hosts are summarized in Table 2 .

\section{Immunohistochemistry}

The immunohistochemical study carried out on gill samples whuch exhubited all different kinds of either granular or amorphous inclusions failed to demonstrate the expression of LPS chlamydial antigen in epitheliocystis causative agents from the sea bream.

Table 1 Length and width in $\mu \mathrm{m}$ (mean \pm SD) of the developmental stages $(R B=$ reticulate body $; B / R C=$ intermediate body/round cell, EB = elementary body; $\mathrm{PLC}=$ primary long cell, ILC $=$ intermediate long cell $i \mathrm{vSC}=$ vacuolated small cell; avSC = non-vacuolated small cell) of epitheliocystis agents from sea bream Sparus aurata

\begin{tabular}{|ccc|}
\hline Stage & Length & Width \\
\hline RB $(n=8)$ & $2.08 \pm 0.89$ & $1.27 \pm 0.45$ \\
IB/RC $(n=20)$ & $0.52 \pm 0.04$ & $0.40 \pm 0.04$ \\
EB $(n=20)$ & $0.54 \pm 0.04$ & $0.41 \pm 0.04$ \\
$\operatorname{PLC}(n=8)$ & $2.51 \pm 0.42$ & $0.59 \pm 0.19$ \\
$\operatorname{ILC}(n=12)$ & $1.30 \pm 0.14$ & $0.54 \pm 0.10$ \\
$\operatorname{vSC}(n=22)$ & $0.68 \pm 0.09$ & $0.52 \pm 0.04$ \\
$\operatorname{avSC}(n=4)$ & $0.63 \pm 0.09$ & $0.44 \pm 0.16$ \\
\hline
\end{tabular}


Table 2. Developmental stages $(\mathrm{RB}=$ reticulate body; $\mathrm{IB} / \mathrm{RC}=$ intermediate body $/$ round cell $; \mathrm{EB}=$ elementary body; PLC $=$ primary long cell; ILC = intermediate long cell; $\mathrm{SC}=$ small cell) of epitheliocystis agents described from different host fish species

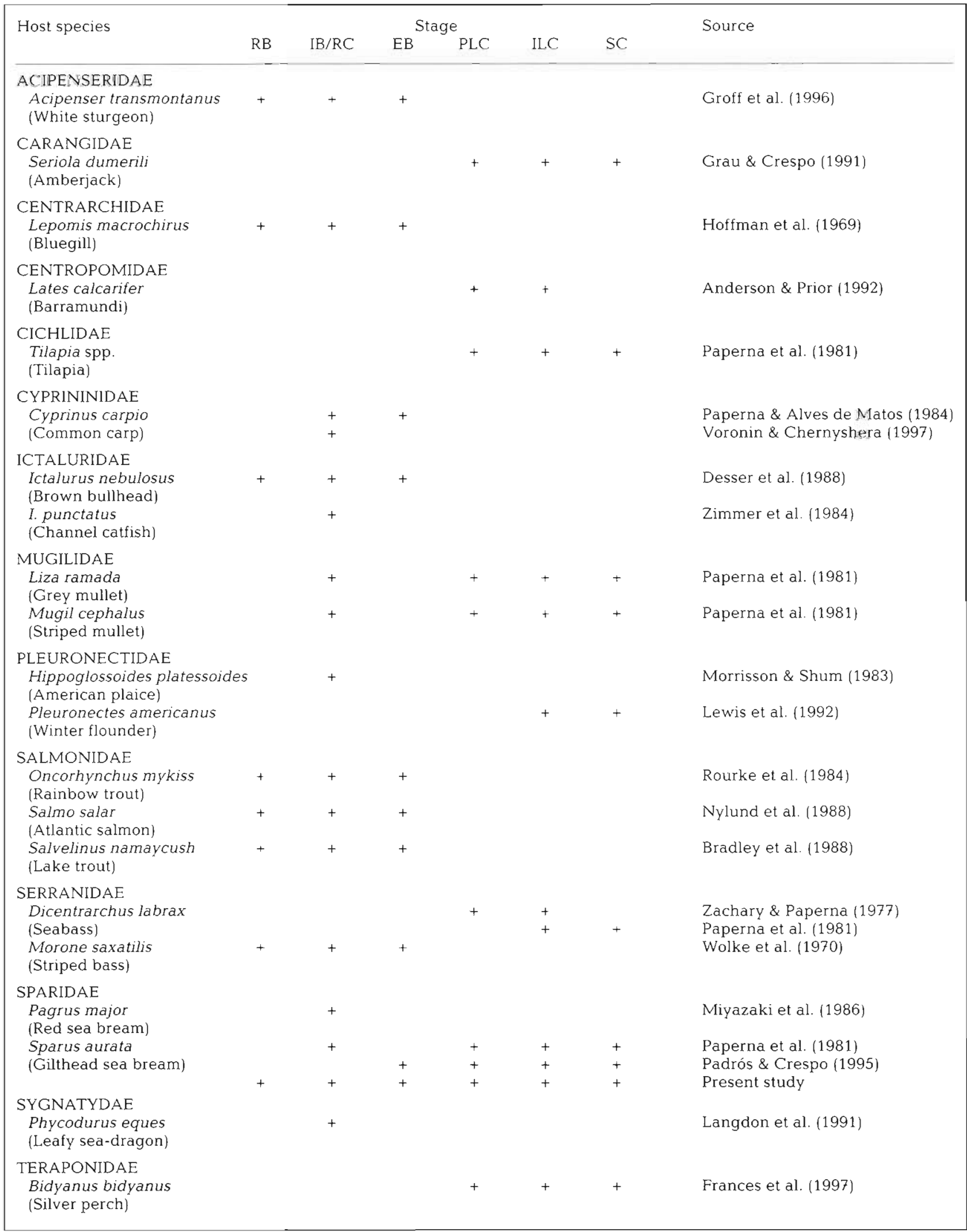




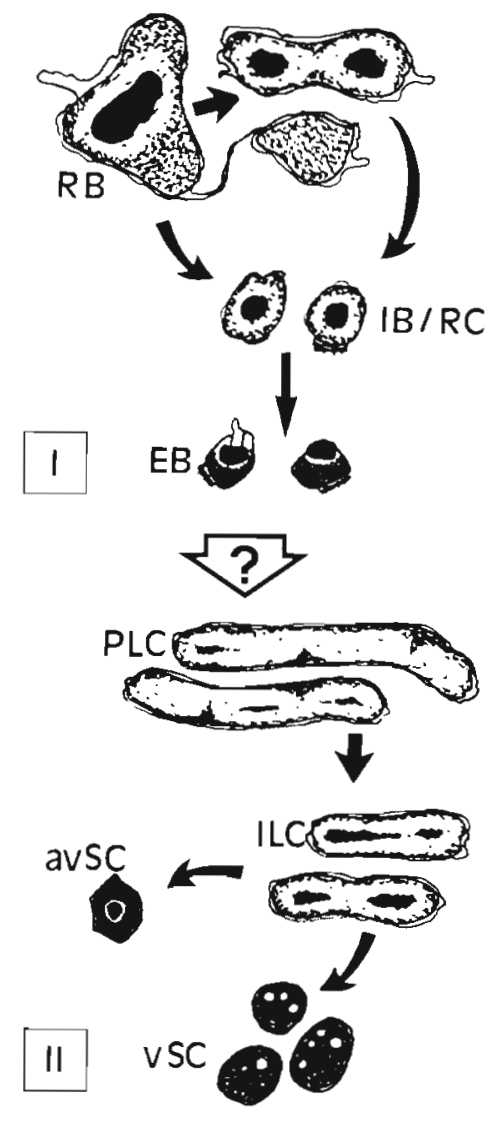

Fig. 7. Diagrammatic summary of the 2 distinct chlamydialike developmental cycles of epitheliocystis agents from sea bream Sparus aurata. Reticulate bodies (RB), intermediate bodies (IB) or 'round' cells (RC), and elementary bodies (EB) are the 3 developmental stages found within granular intracytoplasmatic inclusions (Cycle I). Primary long cells (PLC), intermediate long cells (ILC) and either non-vacuolated (av) or vacuolated (v) small cells (SC) are only found within the amorphous type of cysts (Cycle II)

\section{DISCUSSION}

From data presented here it is apparent that epitheliocystis agents from the sea bream Sparus aurata exhibit 2 distinct pleomorphic biphasic developmental cycles, each within an intracellular membrane-bound inclusion or cyst and including 2 main developmental stages - one highly variable in shape and size and capable of division and the other smaller, electrondenser, non-dividing and uniform in both shape and size.

Prokaryotic organisms within granular inclusions do not elicit any severe proliferative host reaction and share the same ultrastructural features and the same developmental cycle as the chlamydiae of higher vertebrates (see Avakyan \& Popov 1984, Moulder 1984. Wyrick \& Richmond 1989, Vanrompay et al. 1995). Likewise, these prokaryotic organisms are simi- lar to epitheliocystis agents described from different host species such as white sturgeon Acipenser transmontanus, bluegill Lepomis macrochirus, brown bullhead Ictalurus nebulosus, rainbow trout Oncorhynchus mykiss, Atlantic salmon Salmo salar and lake trout Salvelinus namaycush (see Table 2). In all these species, as well as in sea bream Sparus aurata, 3 different stages are reported (Fig. 7; Cycle I): (1) the giant RB or reproductive form, lacking a rigid cell wall (Kordová 1978 ) and, therefore, highly pleomorphic; (2) the condensing form or $\mathrm{IB}_{i}$ and (3) the infective form or $\mathrm{EB}$. Bradley et al. (1988) reported another stage, the 'head and tail' organism, which might be considered as an abnormal form of EB in chlamydiae (Avakyan \& Popov 1984). Our immunohistochemical results are not conclusive. However, 2 ultrastructural features described in Cycle I claim for its 'chlamydia-likeness': (1) surface projections observed in EB opposite the side of electron-dense nucleoid, and (2) multilayered membranes limiting some giant forms of RB. Chlamydiae (but not rickettsiae) possess tubular projections which might serve as channels for transfer of metabolites from the host cytoplasm (Avakyan \& Popov 1984, Moulder 1984, Weiss \& Moulder 1984). Unlike other Gram-negative bacteria, the chlamydia cell wall does not contain peptidoglycan which provides structural stability (Jackson \& Grayston 1997). In EB (but not in RB) stability is provided by a cysteine-rich protein that appears to be important in maintaining the structural rigidity of the infective form (Vanrompay et al. 1995). Because of the lack of rigidity of their cell wall, altered forms of $R B$ are often observed by TEM surrounded by multilayered membranes, which might correspond to cross sections of parallel evaginations of cell wall and cytoplasmic membranes (Avakyan \& Popov 1984).

In our study the 3 morphologies, RB, IB and EB, have been described within a single inclusion, which confirms they are 3 different stages of the same developmental cycle (Cycle $I_{i}$ Fig 7). The immature and mature IB might correspond to the prokaryotic organisms termed dividing and non-dividing 'round' cells (RC) by Paperna et al. (1981) and Paperna \& Alves de Matos (1984). All stages of the developmental Cycle I have dense nucleoids. This agrees with LM observations of inclusions containing these organisms, which all appear granular. Since EB are denser and more closely packed than IB, inclusions containing exclusively EB are the most uniform among the granular cyst population.

None of the stages of developmental Cycle I elicits host reaction in the sea bream Sparus aurata as reported from the 'benign' form of infection in other fish species (Rourke et al. 1984, Bradley et al, 1988. Groff et al. 1996, Nylund et al. 1998). We suggest that the term 'non-proliferative' should be used instead of 
the term 'benign' to avoid confusion between host reaction and pathogenicity. Epitheliocystis hyperinfection by $\mathrm{RB} / \mathrm{IB} / \mathrm{EB}$, although not triggering a proliferative tissue reaction, might compromise respiratory and osmoregulatory processes due to the mechanical occlusion of interlamellar spaces.

The amorphous cysts contain prokaryotic organisms (rod-shaped clear PLC and ILC, the reproductive forms, and electron-dense $\mathrm{SC}$, the infective non-dividing form) which exhibit ultrastructural similarities to those rickettsiae with a chlamydia-like developmental cycle such as Ehrlichia, Neorickettsia or, particularly, Cowdria (Avakyan \& Popov 1984, Weiss \& Moulder 1984, Jongejan et al. 1991). Paperna et al. (1981) previously described PLC, ILC and vacuolated SC from sea bream Sparus aurata, tilapia Tilapia spp., grey mullet Liza ramada and striped mullet Mugil cephalus. PLC, ILC and SC have also been reported from amberjack Seriola dumerili and silver perch Bidyanus bidyanus, and PLC, ILC from barramundi Lates carcarifer and striped bass Morone saxatilis (see Table 2). The description of the 3 different morphologies within a single inclusion confirms that they are 3 different stages of the same developmental cycle (Cycle II; Fig. 7). Cycle I stages are not found within amorphous cysts. Cycle II stages are not encountered within granular cysts.

The present work is the first description of 2 distinct epitheliocystis developmental cycles occurring in the same fish species. Previous studies have already reported some of the stages of either Cycle I or II from the same host (Table 2). In our first description on epitheliocystis from the sea bream from Spanish facilities (Padrós \& Crespo 1995), we only reported EB (Cycle I) and PLC/ILC/SC (Cycle II), possibly due to the fact that the number of cysts we studied by TEM was not sufficient. Paperna et al. (1981), also in the sea bream, reported all stages from Cycle II but only 1 stage from Cycle I (RC). Zachary \& Paperna (1977) reexamined epitheliocystis infected material from striped bass Morone saxatilis previously studied by Wolke et al. (1970) and described rickettsia-like cells within inclusions. They concluded that the RC reported by Wolke et al. (1970) might correspond to cross sections of PLC/ILC. We speculate that epitheliocystis agents from striped bass $M$. saxatilis also exhibited 2 distinct developmental cycles. Likewise, 2 epitheliocystis developmental cycles might occur in striped mullet Mugil cephalus and grey mullet Liza ramada since PLC. ILC, $\mathrm{SC}$ (Cycle II) and RC (Cycle I) have been described in the same individual (Table 2).

Cycle I was the only cycle we found in all the 0.7 to $2 \mathrm{~g}$ sea bream fingerlings examined. Different generations of EB, RB, IB (Cycle I) may take place before EB develop into PLC, which in turn, will give rise to ILC and SC (Cycle II). Paperna \& Alves de Matos (1984) also described different morphologies among either reproductive or infective stages of the epitheliocystis agents from the common carp Cyprinus carpio, suggesting that 2 different developmental cycles could be triggered depending on the type of cell infected. In our TEM study it was not possible to properly identify epitheliocystis host cells due to poor formalin-fixation and to damage caused by the parasite. However, from our SEM observations, it is apparent that either granular or amorphous cysts are mainly found in the interlamellar spaces of the gill filament, where chloride cells are located, which may indicate that the chloride cell is the target for either of the 2 infective agents, EC or SC.

We suggest that other factors such as age of fish, stress or environmental conditions, rather than type of cell infected, might play a role in the switching of Cycle II.

Acknowledgements. The present investigation was partially supported by the CICYT (Comisión Interministerial de Ciencia y Tecnología) grant MAR97-0408-02. The assistance of Drs A. Ramis and N. Majó (Departament de Patologia i Produccions Animals, U.A.B.) is gratefully acknowledged

\section{LITERATURE CITED}

Álvarez-Pellitero P, Crespo S (1995) New disease problems in Mediterranean aquaculture. In: Castelló F, Calderer A (eds) Actas del $V^{\circ}$ Congreso Nacional de Acuicultura. Publicacions de la Universitat de Barcelona, Barcelona, p 86-97

Anderson IG, Prior HC (1992) Subclinical epitheliocystis in barramundi, Lates calcarifer, reared in seacages. Aust Vet Assoc 69:226-227

Avakyan AA, Popov VL (1984) Rickettsiaceae and Chlamydiaceae: comparative electron microscopic studies. Acta Virol 28:159-173

Bradley TM, Newcomer CE, Maxwell KO (1988) Epitheliocystis associated with massive mortalities of cultured lake trout Salvelinus namaycush. Dis Aquat Org 4:9-17

Ceschia G, Makovec E (1995) Epiteliocisti in orate (Sparus aurata) allevate in Italia. Boll Soc It Patol Ittica 17:18-24

Desser S, Paterson W, Steinhagen D (1988) Ultrastructural observations on the causative agent of epitheliocystis in the brown bullhead, Ictalurus nebulosus Lessueur, from Ontario and a comparison with the chlamydiae of higher vertebrates. J Fish Dis 1 1:453-460

Frances J, Tennent R, Nowak BF (1997) Epitheliocystis in silver perch, Bidyanus bidyanus (Mitchell). J Fish Dis 20: $453-457$

Fryer JL, Lannan CN (1994) Rickettsial and chlamydial infections of freshwater and marine fishes, bivalves, and crustaceans. Zool Stud 33:95-107

Grau A, Crespo S (1991) Epitheliocystis in the wild and cultured amberjack, Seriola dumerili Risso: ultrastructural observations. Aquaculture 95:1-6

Groff JM, LaPatra SE, Munn RJ, Anderson ML, Osburn BI (1996) Epitheliocystis infection in cultured white sturgeon (Acipenser transmontanus): antigenic and ultrastructural 
similarities of the causative agent to the chlamydiae. J Vet Diagn Invest 8:172-180

Hoffman GL, Dunbar CE, Wolf K, Zwillenberg LO (1969) Epitheliocystis, a new infectious disease of the bluegill (Lepomis microchirus). Antonie Leeuwenhoek J Microbiol Serol 35:146-158

Jackson LA, Grayston JT (1997) Chlamydia. In: Bittar EE Bittar $N$ (eds) Principles of medical biology, Vol $9 \mathrm{~A}$. Microbiology. JAl Press Inc, Greenwich, p 319-328

Jongejan F, Zandbergen TA, Van De Wiel PA, De Groot M Uilenberg G (1991) The tick-borne rickettsia Cowdria ruminantium has a Chlamydia-like developmental cycle. Onderstepoort J Vet Res 58:227-237

Kordová N (1978) Chlamydiae, rickettsiae, and their cell wall defective variants. Can J Microbiol 24:339-352

Langdon JS, Elliott K, Mackay B (1991) Epitheliocystis in the leafy sea-dragon. Aust Vet J 68:244

Lewis EJ, McLaughlin SM, Bodammer JE, Sawyer TK (1992) Epitheliocystis in ten new host species of marine fish. J Fish Dis 15:267-271

Majó N, Allan GM, O'Loan CJ, Pagès A, Ramis AJ (1995) A sequential histopathologic and immunocytochemical study of chickens, turkey poults and broiler breeders experimentally infected with turkey rhinotracheitis virus. Avian Dis 39:887-896

Miyazaki T, Fujimaki Y, Hatai K (1986) A light and electron microscopic study on epitheliocystis disease in cultured fishes. Bull Jpn Soc Sci Fish 52:199-202

Morrisson C, Shum G (1983) Epitheliocystis in American plaice, Hippoglossoides platessoides (Fabricius). J Fish Dis 6:303-308

Moulder JW (1984) Order II. Chlamydiales Storz and Page $1971,334^{\mathrm{AL}}$ In: Krieg N, Holt JG (eds) Bergey's manual of systematic bacteriology. Williams and Wilkins, Baltimore, p 729-739

Nylund A, Kvenseth AM, Isdal E (1998) A morphological study of the epitheliocystis agent in farmed Atlantic salmon. J Aquat Anim Health 10:43-55

Padrós $F$, Crespo S (1995) Proliferative epitheliocystis associated with monogenean infection in juvenile seabream Sparus aurata in the North East of Spain. Bull Eur Assoc Fish Pathol 15:42-44

Padrós F, Santmartí M, Crespo S (1995) Main disease problems of seabream Sparus aurata cultured in Catalonia. In: Castelló F, Calderer A (eds) Actas del Vo Congreso Nacional de Acuicultura. Publicacions de la Universitat de Barcelona, Barcelona, p 749-753

Editorial responsibility: David Bruno

Aberdeen, Scotland, UK
Paperna I (1977) Epitheliocystis infection in wild and cultured sea bream (Sparus aurata, Sparidae) and grey mullets (Liza ramada, Mugilidae). Aquaculture 10:169-176

Paperna I, Alves de Matos AP (1984) The developmental cycle of epitheliocystis in carp Cyprinus carpio L. J Fish Dis 7:137-147

Paperna I, Baudin-Laurencin F (1979) Parasitic infections of sea bass Dicentrarchus labrax and gilthead sea bream, Sparus aurata, in mariculture facilities in France. Aquaculture 16:173-175

Paperna I, Sabnai I, Zachary A (1981) Ultrastructural studies in piscine epitheliocystis: evidence for a pleomorphic development cycle. J Fish Dis 4:459-472

Rourke AW, Davis RW, Bradley TM (1984) A light and electron microscope study of epitheliocystis in juvenile steelhead trout, Salmo gairdneri Richardson. J Fish Dis 7: 301-309

Szeredi L, Schiller I, Sydler T, Guscetti F, Heinen E, Corboz L, Eggenberger E, Jones GE, Pospischil A (1996) Intestinal Chlamydia in finishing pigs. Vet Pathol 33:369-374

Turnbull JF (1993) Epitheliocystis and salmonid rickettsial septicaemia. In: Inglis V, Roberts RJ, Bromage NR (eds) Bacterial diseases of fish. Blackwell Scientific, Oxford, p 237-254

Vanrompay D, Ducatelle R, Haesebrouck F (1995) Chlamydia psittacci infections: a review with emphasis on avian chlamydiosis. Vet Microbiol 45:93-119

Voronin VN, Chernysheva NB (1997) Epitheliocystis infection in common carp Cyprinus carpio L.: histopathology and pathogenicity. Bull Eur Assoc Fish Pathol 17:137-139

Weiss EA, Moulder JW (1984) Order I. Rickettsiales Gieszczkiewicz 1939, 25 AL In: Krieg N. Holt JG (eds) Bergey's manual of systematic bacteriology. Williams and Wilkins, Baltimore, p $687-729$

Wolke RE, Wyand DS, Khairallah LH (1970) A light and electron microscopic study of epitheliocystis disease in the gills of the Connecticut striped bass (Morone saxatilis) and white perch (Morone americanus). J Comp Pathol 80: $559-563$

Wyrick PB, Richmond SJ (1989). Biology of chlamydiae. JAVMA (J Am Vet Med Assoc) 11:1507-1512

Zachary A. Paperna I (1977) Epitheliocystis disease in the striped bass Morone saxatilis from Chesapeake Bay. Can J Microbiol 23:1404-1414

Zimmer MA, Ewing MS, Kocan KM (1984) Epitheliocystis disease in the channel catfish, Ictalurus punctatus (Rafinesque). J Fish Dis 7:407-410

Submitted: November 2, 1998; Accepted: February 25, 1999 Proofs received from author(s): June 2, 1999 